\title{
suPAR, a Circulating Kidney Disease Factor
}

\author{
Changli Wei ${ }^{\star}$, Ryan Spear, Eunsil Hahm and Jochen Reiser \\ Department of Medicine, Rush University Medical Center, Chicago, IL, United States
}

Urokinase plasminogen activator receptor (UPAR) is a multifaceted, GPI-anchored three-domain protein. Release of the receptor results in variable levels of soluble uPAR (suPAR) in the blood circulation. suPAR levels have been linked to many disease states. In this mini-review, we discuss suPAR as a key circulating molecule mediating kidney disease with a particular focus on differently spliced isoforms.

Keywords: suPAR, isoform, proteinuric disease, kidney, UPAR

\section{THE IMPLICATION OF UPAR IN KIDNEY DISEASE}

The urokinase-type plasminogen activator receptor (uPAR) is a GPI-anchored membrane bound protein involved in many physiological and pathological events. It acts as a receptor for urokinasetype plasminogen activator ( $\mathrm{uPA}$ ), facilitating the generation of activated plasmin, thus playing a role in the directional invasion of migrating cells. It is also implicated in a plethora of cellular responses that include cellular adhesion, differentiation, proliferation and migration in a nonproteolytic fashion as a signaling orchestrator $(1,2)$. uPAR is a member of the lymphocyte antigen 6 (Ly-6) superfamily proteins, containing three domains, namely DI-DIII, as numbered from the $\mathrm{N}$ terminus (3). Protein structure analyses show that uPAR packs into a concave structure with uPA binding to the central cleft, while vitronectin binding to the outside surface $(4,5)$. This special protein structure makes it possible for uPAR to bind different ligands simultaneously, allowing coordinated regulation of proteolysis, cell adhesion and signaling (6-9). Yet, the structure of the unoccupied human UPAR has not been determined, due to the difficulty in crystalizing the protein $(10,11)$.

uPAR is expressed on a variety of cells, including monocyte, lymphocyte, endothelial cells (12). The efforts to examine the expression of uPAR in normal kidney and its alterations in kidney disease started in the mid 1990 (13). Almus-Jacobs et al. found the stimulation of murine uPAR gene by endotoxin (14). Xu et al. observed the upregulation of uPAR expression in the glomeruli and in the arterial walls of thrombotic microangiopathy (15). Within the glomeruli of rejected kidney samples, Tang et al. reported positive immunostaining for UPAR in the mesangial cells, but not in the majority of endothelial cells (16). In a rat model of nephrotoxic nephritis, the induction of glomerular uPAR expression was observed as soon as $1 \mathrm{~h}$ after nephrotoxic serum injection (17). An unusual implication of UPAR in obstructive nephropathy was reported in unilateral ureteral obstruction (UUO) mouse model, whereby uPAR deficiency accelerated renal fibrosis $(18,19)$. These findings suggest that renal uPAR may have protective effects in attenuating the fibrogenic response to some renal injury. In the renal biopsy of acute renal allograft rejection, Roelofs et al. found both UPA and UPAR are upregulated (20). Our team identified podocyte uPAR as an important molecule mediating glomerular filtration barrier function in 2007 (21). We found the induction of glomerular uPAR in both human and rodent proteinuric kidney diseases. Gene transfer of uPAR to podocytes but not that to endothelial cells in UPAR deficiency mice induced proteinuria, suggesting the expression of UPAR from podocytes was required for proteinuria 
development. Mechanistically, uPAR activated $\alpha \mathrm{V} \beta 3$ integrin in podocytes, promoting cell motility and the activation of small GTPase Rac-1 (21).

\section{THE IMPLICATION OF SUPAR IN PROTEINURIC KIDNEY DISEASE}

The presence of soluble form of UPAR or generally suPAR was first reported by Ploug et al. (22), when phorbol 12myristate 13-acetate (PMA)-stimulated U937 cells were treated with bacterial phosphatidylinositol-specific phospholipase-C (PI-PLC). Subsequently, suPAR was detected in many body fluids, such as plasma, serum, urine, saliva, and cerebrospinal fluids. Since then, the elevation of circulating suPAR has been documented in many disease states, reflecting the activation state of the immune system (12).

The initial study of suPAR in proteinuric kidney disease was largely prompted by the concept of a circulating blood factor that causes primary or recurrent focal segmental glomerulosclerosis (FSGS). FSGS refers to a histologic pattern that involves different etiology yet shares a common theme of podocyte injury and/or depletion (23). Generally, FSGS is divided into two categories, primary and secondary. While many studies support the idea that primary FSGS is presumably caused by circulating permeability factor or factors, the identification and characterizing of such factor or factors have been painstakingly challenging. In 2011, our team published the findings that indicate suPAR contributes to primary and recurrent FSGS as a circulating factor (24). suPAR fulfills the criteria of a circulating FSGS factor such as: elevated concentration in patients and the ability to signal to podocytes thereby causing injury and disease. suPAR's injurious activity can be blocked by antibodies against integrin or by lowering suPAR through plasma exchange (25). Some other less characterized candidates for FSGS factor include active proteinases (26), cardiotrophin-like cytokine-1 (27, 28), and protein tyrosine phosphatase receptor O (29).

Using patient samples, we found elevated serum suPAR in two-thirds of primary FSGS, but not in other glomerular disease. In the transplantation subgroup, the mean levels of suPAR, both pre- and post-transplantation, were significantly higher in recurrent FSGS patients than in non-recurrent FSGS patients (24). Like the membrane-bound UPAR, suPAR activated $\beta 3$ integrin in podocytes. Sustained expression of the secreted form of mouse UPAR induced proteinuria as well as kidney pathological changes in mice (24). In a follow-up study with two independent primary FSGS cohorts, 70 patients from the FSGS clinical trial (CT) and 94 patients from PodoNet, we found the increase of circulating suPAR in $84.3 \%$ of CT, $55.3 \%$ of PodoNet FSGS patients, compared with $6 \%$ of controls (30). Note that CT is a North-America based randomized study that compared the efficacy of cyclosporine A with the combination of mycophenolate mofetil and dexamethasone. Key inclusion criteria are age 2-40 years, eGFR $>40 \mathrm{ml} / \mathrm{min}$ per $1.73 \mathrm{~m}^{2}$, biopsy-proven FSGS, and resistance to corticosteroid therapy. PodoNet however is a Europe-based consortium for clinical, genetic, and experimental study of SRNS. The inclusion criteria are children (age 0-18 years) with steroid-resistant nephrotic syndrome (SRNS) based on management protocols at the participating medical centers and adults with familial SRNS. The difference in patient population could partially account for the difference in suPAR levels with these two primary FSGS cohorts.

Unsurprisingly, these reports on the implication of suPAR as an FSGS factor soon generated excitement and follow-up studies $(31,32)$. Case reports emerged showing that lowering circulating suPAR levels through plasmapheresis or immunoadsorption could reduce proteinuria in recurrent FSGS (33), making it an effective therapy for some transplant FSGS patients $(34,35)$. Conversely, transmission of elevated suPAR from a mother with FSGS to her child was correlated to the child being born with proteinuria (36). Morphologically, podocyte effacement could be closely linked to suPAR levels at the time of post-transplantation FSGS occurrence (37). In line with these clinical observations, our findings obtained from animal experiments support the causative correlation between suPAR levels and renal function (38). Using a series of experimental approaches, including bone marrow transplantation and adoptive cell transfer, we discovered that bone marrow (BM)-derived immature myeloid cells (IMCs) are likely a main source of circulating suPAR, thereby contributing to proteinuric kidney diseases. These findings, in agreement with early observations (39), suggest the functional contribution of BM to kidney function and BM-derived IMCs as the possible origin of circulating suPAR responsible for renal injury. As evidence, we have shown that suPAR-generating cells transferred from proteinuric mice are essential for the induction of proteinuria and a concomitant suPAR increase in healthy mice (38) (Figure 1).

Particularly, in the first 5 years after the initial discovery of suPAR as a FSGS factor, not all studies with suPAR have resulted in supporting conclusions. This could be attributed to technical reasons such as differences in biological models or assays or a lack of power in some cohort-based studies. In a single center study of idiopathic FSGS in children, Bock et al. did not find the difference in serum suPAR levels among FSGS, non-FSGS glomerular disease, non-glomerular kidney disease and healthy controls (40). Subsequently, there were several studies from different groups questioning the usefulness of serum suPAR as a diagnostic marker for FSGS. The possibility of retention of suPAR due to decreased glomerular filtration rate (GFR) has been raised as well (41-44). The main argument was the relative unspecific nature of an elevated circulating suPAR, which could be observed in FSGS, but also in non-FSGS kidney disease and in many nonkidney disease. This discrepancy was clarified in a large cohort study establishing suPAR as a risk factor for chronic kidney disease (CKD) (45). Conflicting conclusions were arisen from different animal studies as well. We showed that the injection of full-length mouse recombinant suPAR protein (derived from NS0 cells, Fc Chimera, R\&D systems) caused a mild proteinuria in uPAR knockout $\left(\right.$ Plaur $\left.^{-/}\right)$mice. Whereas, Cathelin et al. did not detect proteinuria in wild type C57BL/6J mice injected with mouse full length suPAR protein purified from NS0 cells or a monomeric mouse full length uPAR isolated from eukaryotic S2 cells (46). In contrast to our experimental model where the secreted form of mouse uPAR was expressed via electroporation 
A

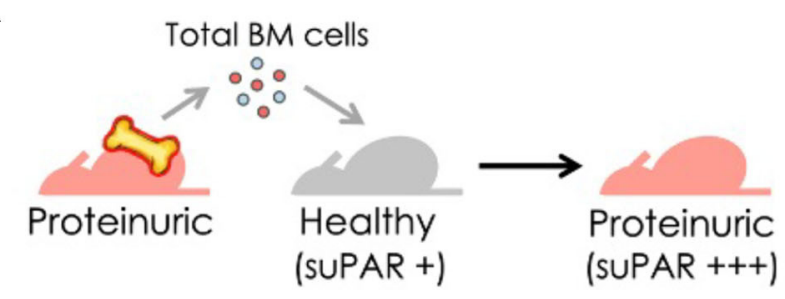

C

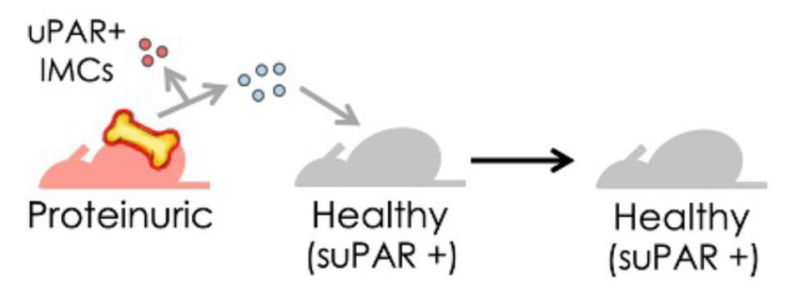

B

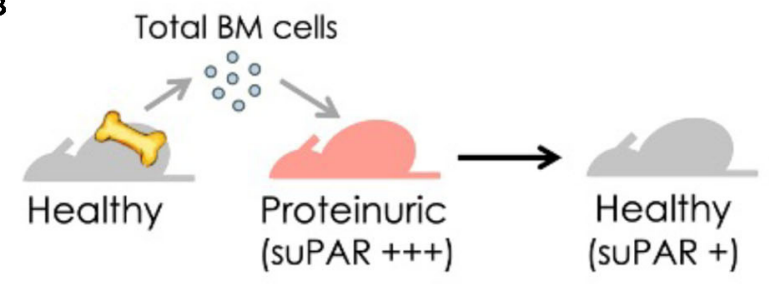

FIGURE 1 | Bone marrow (BM)-derived immature myeloid cells (IMCs), newly identified as a cellular source of suPAR, transfer disease from proteinuric to healthy mice. (A) Transfer of BM cells from proteinuric to healthy mice results in proteinuria and increases blood suPAR levels. (B) Replacement with BM cells from healthy mice significantly reduces suPAR levels and subsequently improves renal function in proteinuric mice. (C) The removal of uPAR-expressing IMCs prior to transfer of BM cells from proteinuric to healthy mice protects mice from proteinuria.

in wild type C57BL/6J mice (24), Spinale et al. utilized a fulllength mouse suPAR transgenic floxed FVB mouse model. While the induction of mouse suPAR in the liver was achieved by retroorbital injection of Adeno Associated Virus 8 particles that carry a hepatocyte-specific Cre recombinase, these mice did not develop proteinuria up to 44 days (47). These seemingly conflicting studies employed different models, methods and human patient cohorts, and If interpreted more carefully in their respective close context would have caused less confusion. As pointed out by late Schlondorff, these discrepancies should not discourage further research on the potential roles of suPAR in proteinuric kidney disease, including FSGS (48), and indeed they did not. In 2014, Delville et al. published a circulating antibody panel for pre-transplant prediction of FSGS recurrence after kidney transplantation. In their study, CD40 autoantibody alone had the best correlation (78\% accuracy) with recurrent FSGS risk after transplantation; interestingly injection of CD40 autoantibody obtained from recurrent FSGS patients enhanced human suPARmediated proteinuria in wild type mice, suggesting the possible synergy between CD40 autoantibody and suPAR (49). Later, Alfano et al. found that full-length human suPAR downregulated nephrin expression in human primary podocytes. Additionally they found infusion of this same human full length suPAR protein into uPAR knockout mice induces proteinuria (50). In individuals of recent African ancestry, variants in APOL1 have been associated with certain forms of CKD. In two large unrelated cohorts, Hayek et al. found that decline in kidney function associated with APOL1 risk variants is dependent on plasma suPAR levels. Their study suggested the synergy of circulating suPAR and APOL1 variant G1 or G2 on $\alpha \mathrm{V} \beta 3$ integrin activation is an underlying mechanism (51). Needless to say, the initial debate regarding suPAR and proteinuric kidney disease triggered and/or intensified the investigation of suPAR as a biomarker and risk factor for $\mathrm{CKD}$ and acute kidney injury (AKI), the details of which will be reviewed elsewhere.

To further understand the possible causative role of suPAR, we have created three different transgenic mouse models, constitutively expressing full-length mouse suPAR (muPAR1), secreted form of mouse suPAR (muPAR2) and mouse suPAR DIIDIII fragment under AP2 promoter, respectively. Compared to muPAR1, muPAR2 does not possess GPI anchor sequence and only have an intact DI. In certain experiments, the transgenic mice were fed with high fat diet to induce the expression of mouse suPAR. Interestingly, we observed different kidney pathologies with these transgenic mice: 4 months into high fat diet induction, muPAR1 transgenic mice developed significant low grade proteinuria in about one third of the mice (38); 6 months after high fat diet treatment, proteinuria became severe in some but not all muPAR1 transgenic mice (52). A small portion of muPAR1 transgenic mice developed spontaneous proteinuria by 1 year old without high fat diet treatment. In contrast, most muPAR2 transgenic mice developed spontaneous proteinuria by 2 months old without high fat diet. With high fat diet treatment, muPAR2 transgenic mice presented chronic and progressive proteinuria. By high fat diet induction for 6 months, some muPAR2 transgenic mice demonstrated a severe proteinuric kidney disease characteristic of FSGS changes. Mechanistically, msuPAR2 requires the presence of $\beta 3$ integrinSrc signaling to generate proteinuria $(52,53)$. Collectively, these findings indicate that different forms of mouse suPAR generate kidney disease state with different severity, further reflecting the complexity of suPAR biology. 


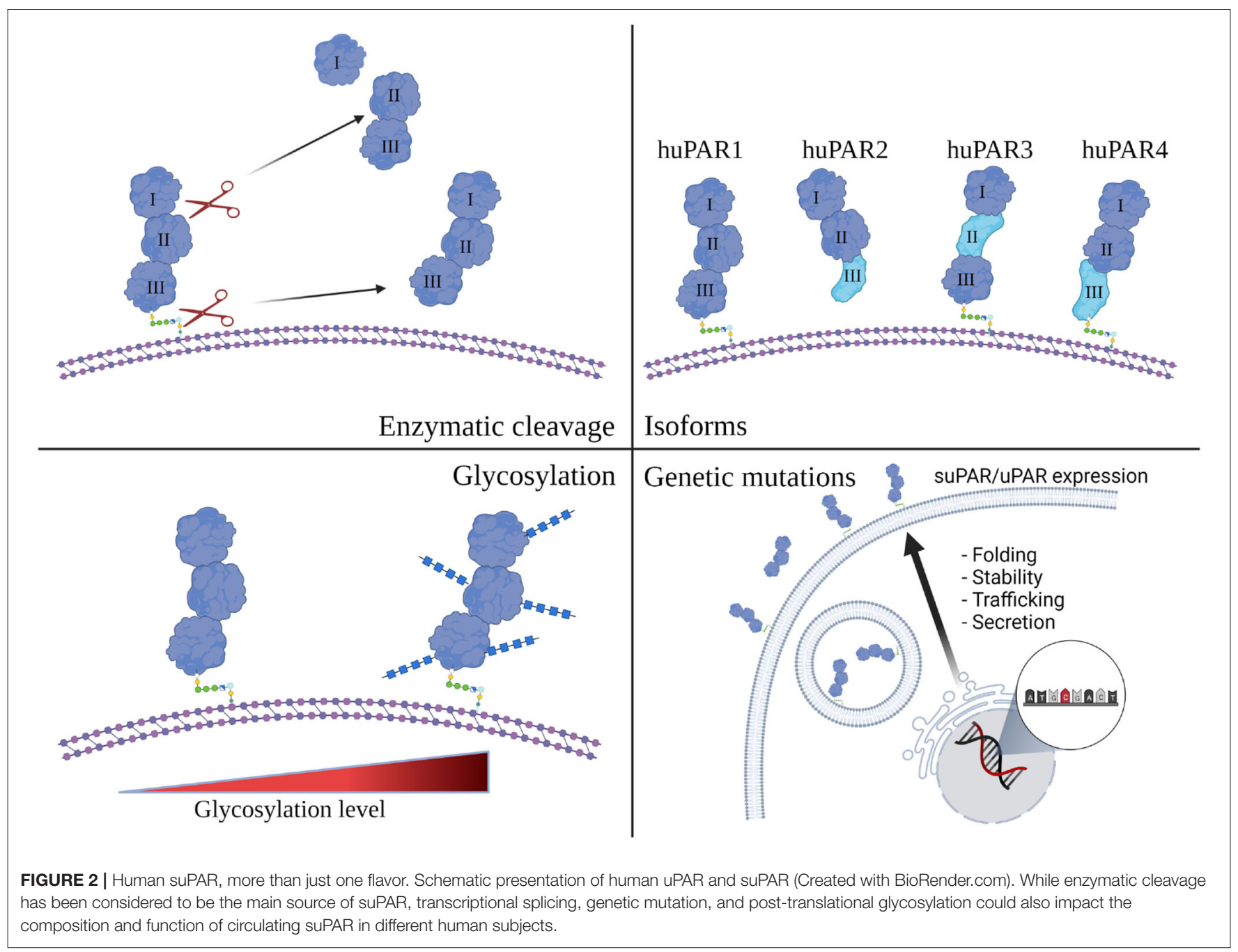

\section{SUPAR/UPAR, MORE THAN JUST ONE LOOK}

How can we understand the multifaceted role of suPAR in kidney disease? While generally known as suPAR, it clearly has more than one form. It has been documented that cleavage of GPI anchor releases full-length suPAR from membranebound UPAR (22). Numerous studies have indicated that fulllength suPAR is functional (12). It retains uPAR's ability to bind to UPA, and suPAR binds vitronectin and integrins as well $(9,54,55)$. As suPAR and UPAR can be cleaved at the linker region between DI and DII by a variety of enzymes (56), they generate DI fragment and DIIDIII fragment. Both fragments have been detected in body fluids $(57,58)$. DIIDIII fragment, while cannot efficiently bind uPA or vitronectin is active as it possess chemotactic properties shown by many studies (59-61). In addition to different suPAR fragments, there are other modifications that could impact circulating suPAR composition and function as well, including post-translational glycosylation, genetic mutation, and different isoforms derived from alternative splicing (Figure 2). The amino acid sequence for human uPAR/suPAR contains five N-linked glycosylation sites affecting the molecule mass and possibly the function of these proteins. Several different glycosylated variants have been reported in different cell types (62). Glycosylation profiling of a recombinant suPAR expressed in Chinese hamster ovary cells indicated that only four sites were utilized (63). How different glycosylated suPAR variants function in human body remains unknown. Recently, there are several studies presenting different uPAR genetic variants, correlating to circulating suPAR levels or not $(64,65)$. Understanding the role of these uPAR genetic mutations in human physiology and disease will be an exciting research avenue in the future.

\section{UPAR ISOFORM AND PROTEINURIC KIDNEY DISEASE}

Notably, uPAR has multiple isoforms both in human and in mice due to alternative splicing of the seven encoding exons (Table 1) $(66,67)$. About three decades ago, two alternatively spliced mouse uPAR mRNAs were identified in the gastrointestinal tract, with 
TABLE 1 | Major UPAR isoforms in mouse and human.

\begin{tabular}{|c|c|c|c|c|c|c|c|}
\hline & Isoform & Exon & Domains & GPI anchor & $\begin{array}{l}\text { Length (Amino } \\
\text { acid) }\end{array}$ & Nucleotide ID & Protein ID \\
\hline \multirow[t]{2}{*}{ Mouse } & $\begin{array}{l}\text { Isoform } 1 \\
\text { canonical form, } \\
\text { muPAR1 }\end{array}$ & 7 Exons (1-7) & $\begin{array}{l}\text { Three intact } \\
\text { domains (I, II, III) }\end{array}$ & Yes & 327 & NM_011113 & NP_035243 \\
\hline & $\begin{array}{l}\text { Isoform } 2 \\
\text { secreted, muPAR2 }\end{array}$ & $\begin{array}{l}\text { Exons } 5 \text { to } 7 \\
\text { missing }\end{array}$ & $\begin{array}{l}\text { DIII and part of DII } \\
\text { missing }\end{array}$ & No & 222 & BC010309 & CAA44575 \\
\hline \multirow[t]{4}{*}{ Human } & $\begin{array}{l}\text { Isoform } 1 \\
\text { canonical form, } \\
\text { huPAR1 }\end{array}$ & 7 Exons (1-7) & $\begin{array}{l}\text { Three intact } \\
\text { domains (I, II, III) }\end{array}$ & Yes & 335 & NM_002659 & NP_002650 \\
\hline & $\begin{array}{l}\text { Isoform } 2 \\
\text { secreted, huPAR2 }\end{array}$ & Exon 7 missing & $\begin{array}{l}\text { C-terminal part of } \\
\text { DIII missing }\end{array}$ & No & 281 & NM_001005376 & NP_001005376 \\
\hline & Isoform 3, huPAR3 & Exon 5 missing & Part of DII missing & Likely & 290 & NM_001005377 & NP_001005377 \\
\hline & Isoform 4, huPAR4 & Exon 6 missing & $\begin{array}{l}\mathrm{N} \text {-terminal part of } \\
\text { DIII missing }\end{array}$ & Likely & 286 & NM_001301037 & NP_001287966 \\
\hline
\end{tabular}

the full length, canonical form (muPAR1) localized in the luminal epithelial cells, and the shorter secreted form (muPAR2) found in the basal epithelial cells (66). Unlike muPAR1, which has 3 intact domains (DI to DIII) and 7 predicted sites of glycosylation, muPAR2 has only intact DI, encoded by exons 2 and 3, and part of DII as encoded by exon 4, missing the rest of the native protein (whole DIII and part of DII, encoded by exons 5-7), including GPI anchor. Judged from its amino acid sequence, msuPAR2 was once considered to be unstable due to its number of cysteine residues (68). We originally cloned muPAR2 mRNA (GenBank ID, BC010309) from cultured mouse podocytes, and found its protein interacting with integrin $\beta 3$; once expressed in C57BL/6 mice via electroporation, muPAR2 induced proteinuric kidney disease (24). The pathogenesis of muPAR2 was later confirmed in muPAR2 transgenic mice that developed a chronic kidney disease, resembling FSGS. In addition, we purified msuPAR2 protein from HEK cells and characterized it as a stable protein, forming a dimer comprising DI and part of DII. The single long strand of $\beta$-sheet in the DII region might pair with the strand from its dimer partner (52). Our studies indicate that some form of suPAR causes FSGS-like changes at least in mice $(24,52)$.

Compared to mouse uPAR, human uPAR has more splicing isoforms. So far, at least 4 major human uPAR isoforms have been documented in different human cells and tissues. While we detected these isoforms in human peripheral mononuclear cells (PBMC) by real-time quantitative PCR (52), HagemannJensen et al. reported the presence of multiple UPAR isoforms in different $\mathrm{T}$ cells, monocytes and HEK cells by single cell RNA sequencing (69). Some of these uPAR isoforms could be detected in human glomeruli as well (personal communication with Dr. Mattias Kretzler from University of Michigan). Human isoform 1 (huPAR1) is equivalent to canonical muPAR1, with three intact Ly6/uPAR domains and a GPI anchor. Human isoform 2 (huPAR2) has a deletion of exon 7, and lacks a GPI anchor sequence. As with muPAR2, huPAR2 could provide the natural (secreted and uncleaved) source of suPAR. Human isoform 3 (huPAR3) has a deletion of exon 5, hence lacks the three C-terminal $\beta$-strands in DII. Human isoform 4 (huPAR4) has an in-frame deletion of exon 6, which contributes the N-terminal sheet assembly to DIII, but retains the 3 C-terminal strands of DIII and the GPI anchor. How do these splicing isoforms impact suPAR's composition and function remains unclear. Notably, the currently available ELISA kits are all utilizing different antibodies developed against huPAR1, the canonical form, yet they present different suPAR levels (70). While they can detect the full length human suPAR and DIIDIII fragments derived from huPAR1, they cannot efficiently detect most of alternative human UPAR isoforms.

What is the implication of different human UPAR isoforms in kidney? Since muPAR2 is associated with FSGS-like kidney changes in our mouse model, it is possible that overexpression of one or more of these human isoforms could be associated with the development of FSGS. Among these human uPAR isoforms, huPAR3 seems to be the closest to muPAR2 at least structurally. It likely forms the same dimer assembly as we observe in the msuPAR2 structure (52). Indeed, transient expression of huPAR3 in $\mathrm{C} 57 \mathrm{BL} / 6 \mathrm{~J}$ mice induced proteinuria (unpublished data). In no doubt, further studies on alternative human UPAR isoforms are required to determine their respective roles in the pathogenesis in kidney disease.

In summary, elevation of suPAR is a circulating risk factor for kidney disease, including FSGS. Certain form of suPAR (i.e., muPAR2) causes FSGS-like changes in mice. The complexity of suPAR derived from different enzymatic cleavage, transcriptional splicing and post-translational modification may explain suPAR/uPAR's multifaceted roles. New technologies such as single cell based deep sequencing and proteomic analysis should help understand their respective underlying mechanisms in different disease settings. Detecting the different circulating UPAR isoforms in human samples could possibly provide differentiating diagnostic or prognostic value with different suPAR related disease. 


\section{AUTHOR CONTRIBUTIONS}

CW, RS, EH, and JR wrote the manuscript. All authors contributed to the article and approved the submitted version.

\section{REFERENCES}

1. Blasi F, Carmeliet P. uPAR: a versatile signalling orchestrator. Nat Rev Mol Cell Biol. (2002) 3:932-43. doi: 10.1038/nrm977

2. Smith HW, Marshall CJ. Regulation of cell signalling by uPAR. Nat Rev Mol Cell Biol. (2010) 11:23-36. doi: 10.1038/nrm2821

3. Behrendt N, Ploug M, Patthy L, Houen G, Blasi F, Dano K. The ligand-binding domain of the cell surface receptor for urokinase-type plasminogen activator. J Biol Chem. (1991) 266:7842-7. doi: 10.1016/S0021-9258(20)89526-X

4. Huai Q, Mazar AP, Kuo A, Parry GC, Shaw DE, Callahan J, et al. Structure of human urokinase plasminogen activator in complex with its receptor. Science. (2006) 311:656-9. doi: 10.1126/science.1121143

5. Llinas P, Le Du MH, Gardsvoll H, Dano K, Ploug M, Gilquin B, et al. Crystal structure of the human urokinase plasminogen activator receptor bound to an antagonist peptide. EMBO J. (2005) 24:165563. doi: $10.1038 /$ sj.emboj.7600635

6. Wei Y, Waltz DA, Rao N, Drummond RJ, Rosenberg S, Chapman HA. Identification of the urokinase receptor as an adhesion receptor for vitronectin. J Biol Chem. (1994) 269:323808. doi: 10.1016/S0021-9258(18)31646-6

7. Huai Q, Zhou A, Lin L, Mazar AP, Parry GC, Callahan J, et al. Crystal structures of two human vitronectin, urokinase and urokinase receptor complexes. Nat Struct Mol Biol. (2008) 15:422-3. doi: 10.1038/nsmb.1404

8. Gardsvoll H, Ploug M. Mapping of the vitronectin-binding site on the urokinase receptor: involvement of a coherent receptor interface consisting of residues from both domain I and the flanking interdomain linker region. $J$ Biol Chem. (2007) 282:13561-72. doi: 10.1074/jbc.M610184200

9. Sidenius N, Andolfo A, Fesce R, Blasi F. Urokinase regulates vitronectin binding by controlling urokinase receptor oligomerization. J Biol Chem. (2002) 277:27982-90. doi: 10.1074/jbc.M111736200

10. Mertens HD, Kjaergaard M, Mysling S, Gardsvoll H, Jorgensen TJ, Svergun DI, et al. A flexible multidomain structure drives the function of the urokinasetype plasminogen activator receptor (uPAR). J Biol Chem. (2012) 287:3430415. doi: $10.1074 /$ jbc.M112.398404

11. Xu X, Gardsvoll H, Yuan C, Lin L, Ploug M, Huang M. Crystal structure of the urokinase receptor in a ligand-free form. J Mol Biol. (2012) 416:62941. doi: 10.1016/j.jmb.2011.12.058

12. Thuno M, Macho B, Eugen-Olsen J. suPAR: the molecular crystal ball. Dis Markers. (2009) 27:157-72. doi: 10.1155/2009/504294

13. Wagner SN, Atkinson MJ, Wagner C, Hofler H, Schmitt M, Wilhelm O. Sites of urokinase-type plasminogen activator expression and distribution of its receptor in the normal human kidney. Histochem Cell Biol. (1996) 105:53-60. doi: 10.1007/BF01450878

14. Almus-Jacobs F, Varki N, Sawdey MS, Loskutoff DJ. Endotoxin stimulates expression of the murine urokinase receptor gene in vivo. Am J Pathol. (1995) 147:688-98.

15. Xu Y, Hagege J, Mougenot B, Sraer JD, Ronne E, Rondeau E. Different expression of the plasminogen activation system in renal thrombotic microangiopathy and the normal human kidney. Kidney Int. (1996) 50:20119. doi: 10.1038/ki.1996.523

16. Tang WH, Friess H, di Mola FF, Schilling M, Maurer C, Graber HU, et al. Activation of the serine proteinase system in chronic kidney rejection. Transplantation. (1998) 65:162834. doi: 10.1097/00007890-199806270-00015

17. Xu Y, Berrou J, Chen X, Fouqueray B, Callard P, Sraer JD, et al. Induction of urokinase receptor expression in nephrotoxic nephritis. Exp Nephrol. (2001) 9:397-404. doi: 10.1159/000052638

18. Zhang G, Kim H, Cai X, Lopez-Guisa JM, Alpers CE, Liu Y, et al. Urokinase receptor deficiency accelerates renal fibrosis in obstructive nephropathy. J Am Soc Nephrol. (2003) 14:1254-71. doi: 10.1097/01.ASN.0000064292.37793.FB

\section{FUNDING}

This work was supported by RO1DK125858, RO1DK109720, R01DK113761 (JR and CW), and RO1DK125394 (EH).

19. Zhang G, Kim H, Cai X, Lopez-Guisa JM, Carmeliet P, Eddy AA. Urokinase receptor modulates cellular and angiogenic responses in obstructive nephropathy. J Am Soc Nephrol. (2003) 14:1234-53. doi: 10.1097/01.ASN.0000064701.70231.3F

20. Roelofs JJ, Rowshani AT, van den Berg JG, Claessen N, Aten J, ten Berge IJ, et al. Expression of urokinase plasminogen activator and its receptor during acute renal allograft rejection. Kidney Int. (2003) 64:184553. doi: 10.1046/j.1523-1755.2003.00261.x

21. Wei C, Moller CC, Altintas MM, Li J, Schwarz K, Zacchigna S, et al. Modification of kidney barrier function by the urokinase receptor. Nat Med. (2008) 14:55-63. doi: 10.1038/nm1696

22. Ploug M, Ronne E, Behrendt N, Jensen AL, Blasi F, Dano K. Cellular receptor for urokinase plasminogen activator. Carboxyl-terminal processing and membrane anchoring by glycosyl-phosphatidylinositol. J Biol Chem. (1991) 266:1926-33. doi: 10.1016/S0021-9258(18)52382-6

23. Rosenberg AZ, Kopp JB. Focal segmental glomerulosclerosis. Clin J Am Soc Nephrol. (2017) 12:502-17. doi: 10.2215/CJN.05960616

24. Wei C, El Hindi S, Li J, Fornoni A, Goes N, Sageshima J, et al. Circulating urokinase receptor as a cause of focal segmental glomerulosclerosis. Nat Med. (2011) 17:952-60. doi: 10.1038/nm.2411

25. Zeier M, Reiser J. suPAR and chronic kidney disease-a podocyte story. Pflugers Arch. (2017) 469:1017-20. doi: 10.1007/s00424-017-2026-7

26. Musante L, Candiano G, Bruschi M, Zennaro C, Carraro M, Artero $\mathrm{M}$, et al. Characterization of plasma factors that alter the permeability to albumin within isolated glomeruli. Proteomics. (2002) 2:197205.3. doi: 10.1002/1615-9861(200202)2:2<197::AID-PROT197>3.0.CO;2-6

27. McCarthy ET, Sharma M, Savin VJ. Circulating permeability factors in idiopathic nephrotic syndrome and focal segmental glomerulosclerosis. Clin J Am Soc Nephrol. (2010) 5:2115-21. doi: 10.2215/CJN.03800609

28. Savin VJ, Sharma M, Zhou J, Gennochi D, Fields T, Sharma R, et al. Renal and hematological effects of CLCF-1, a B-cell-stimulating cytokine of the IL-6 family. J Immunol Res. (2015) 2015:714964. doi: 10.1155/2015/714964

29. Charba DS, Wiggins RC, Goyal M, Wharram BL, Wiggins JE, McCarthy ET, et al. Antibodies to protein tyrosine phosphatase receptor type O (PTPro) increase glomerular albumin permeability (P(alb)). Am J Physiol Renal Physiol. (2009) 297:F138-44. doi: 10.1152/ajprenal.00122.2008

30. Wei C, Trachtman H, Li J, Dong C, Friedman AL, Gassman JJ, et al. Circulating suPAR in two cohorts of primary FSGS. J Am Soc Nephrol. (2012) 23:2051-9. doi: 10.1681/ASN.2012030302

31. Maas RJ, Deegens JK, Wetzels JF. Serum suPAR in patients with FSGS: trash or treasure? Pediatr Nephrol. (2013) 28:1041-8. doi: 10.1007/s00467-013-2452-5

32. Trachtman H, Reiser J. suPAR is the circulating factor in some but not all FSGS. Nat Rev Nephrol. (2014) 10:610. doi: 10.1038/nrneph.2014.113-c1

33. Morath C, Wei C, Macher-Goeppinger S, Schwenger V, Zeier M, Reiser J. Management of severe recurrent focal segmental glomerulosclerosis through circulating soluble urokinase receptor modification. Am J Ther. (2013) 20:226-9. doi: 10.1097/MJT.0b013e3182811aca

34. Schenk H, Muller-Deile J, Schmitt R, Brasen JH, Haller H, Schiffer M. Removal of focal segmental glomerulosclerosis (FSGS) factor suPAR using CytoSorb. $J$ Clin Apher. (2017) 32:444-52. doi: 10.1002/jca.21538

35. Alachkar N, Li J, Matar D, Vujjini V, Alasfar S, Tracy M, et al. Monitoring suPAR levels in post-kidney transplant focal segmental glomerulosclerosis treated with therapeutic plasma exchange and rituximab. BMC Nephrol. (2018) 19:361. doi: 10.1186/s12882-018-1177-x

36. Kemper MJ, Wei C, Reiser J. Transmission of glomerular permeability factor soluble urokinase plasminogen activator receptor (suPAR) from a mother to child. Am J Kidney Dis. (2013) 61:352. doi: 10.1053/j.ajkd.2012.10.011

37. Alachkar N, Wei C, Arend LJ, Jackson AM, Racusen LC, Fornoni $A$, et al. Podocyte effacement closely links to suPAR levels at time of posttransplantation focal segmental glomerulosclerosis 
occurrence and improves with therapy. Transplantation. (2013) 96:649-56. doi: 10.1097/TP.0b013e31829eda4f

38. Hahm E, Wei C, Fernandez I, Li J, Tardi NJ, Tracy M, et al. Bone marrow-derived immature myeloid cells are a main source of circulating suPAR contributing to proteinuric kidney disease. Nat Med. (2017) 23:100-6. doi: 10.1038/nm. 4242

39. Nishimura $M$, Toki J, Sugiura $K$, Hashimoto $F$, Tomita $T$, Fujishima $\mathrm{H}$, et al. Focal segmental glomerular sclerosis, a type of intractable chronic glomerulonephritis, is a stem cell disorder. J Exp Med. (1994) 179:1053-8. doi: 10.1084/jem.179.3. 1053

40. Bock ME, Price HE, Gallon L, Langman CB. Serum soluble urokinasetype plasminogen activator receptor levels and idiopathic FSGS in children: a single-center report. Clin J Am Soc Nephrol. (2013) 8:130411. doi: 10.2215/CJN.07680712

41. Meijers B, Maas RJ, Sprangers B, Claes K, Poesen R, Bammens B, et al. The soluble urokinase receptor is not a clinical marker for focal segmental glomerulosclerosis. Kidney Int. (2014) 85:636-40. doi: 10.1038/ki.2013.505

42. Wada T, Nangaku M, Maruyama S, Imai E, Shoji K, Kato S, et al. A multicenter cross-sectional study of circulating soluble urokinase receptor in Japanese patients with glomerular disease. Kidney Int. (2014) 85:6418. doi: 10.1038/ki.2013.544

43. Sinha A, Bajpai J, Saini S, Bhatia D, Gupta A, Puraswani M, et al. Serum-soluble urokinase receptor levels do not distinguish focal segmental glomerulosclerosis from other causes of nephrotic syndrome in children. Kidney Int. (2014) 85:649-58. doi: 10.1038/ki.2013.546

44. Harita Y, Ishizuka K, Tanego A, Sugawara N, Chikamoto H, Akioka Y, et al. Decreased glomerular filtration as the primary factor of elevated circulating suPAR levels in focal segmental glomerulosclerosis. Pediatr Nephrol. (2014) 29:1553-60. doi: 10.1007/s00467-014-2808-5

45. Hayek SS, Sever S, Ko YA, Trachtman H, Awad M, Wadhwani S, et al. Soluble Urokinase receptor and chronic kidney disease. N Engl J Med. (2015) 373:1916-25. doi: 10.1056/NEJMoa1506362

46. Cathelin D, Placier S, Ploug M, Verpont MC, Vandermeersch S, Luque Y, et al. Administration of recombinant soluble urokinase receptor per se is not sufficient to induce podocyte alterations and proteinuria in mice. J Am Soc Nephrol. (2014) 25:1662-8. doi: 10.1681/ASN.2013040425

47. Spinale JM, Mariani LH, Kapoor S, Zhang J, Weyant R, Song PX, et al. Nephrotic syndrome study, a reassessment of soluble urokinase-type plasminogen activator receptor in glomerular disease. Kidney Int. (2015) 87:564-74. doi: 10.1038/ki.2014.346

48. Schlondorff D. Are serum suPAR determinations by current ELISA methodology reliable diagnostic biomarkers for FSGS? Kidney Int. (2014) 85:499-501. doi: 10.1038/ki.2013.549

49. Delville M, Sigdel TK, Wei C, Li J, Hsieh SC, Fornoni A, et al. A circulating antibody panel for pretransplant prediction of FSGS recurrence after kidney transplantation. Sci Transl Med. (2014) 6:256ra136. doi: 10.1126/scitranslmed.3008538

50. Alfano M, Cinque P, Giusti G, Proietti S, Nebuloni M, Danese S, et al. Full-length soluble urokinase plasminogen activator receptor down-modulates nephrin expression in podocytes. Sci Rep. (2015) 5:13647. doi: 10.1038/srep 13647

51. Hayek SS, Koh KH, Grams ME, Wei C, Ko YA, Li J, et al. A tripartite complex of suPAR, APOL1 risk variants and alphavbeta3 integrin on podocytes mediates chronic kidney disease. Nat Med. (2017) 23:94553. doi: $10.1038 / \mathrm{nm} .4362$

52. Wei C, Li J, Adair BD, Zhu K, Cai J, Merchant M, et al. uPAR isoform 2 forms a dimer and induces severe kidney disease in mice. J Clin Invest. (2019) 129:1946-59. doi: 10.1172/JCI124793

53. Kopp JB, Heymann J. c-Src is in the effector pathway linking UPAR and podocyte injury. J Clin Invest. (2019) 129:1827-9. doi: 10.1172/JCI127927

54. Masucci MT, Pedersen N, Blasi F. A soluble, ligand binding mutant of the human urokinase plasminogen activator receptor. J Biol Chem. (1991) 266:8655-8. doi: 10.1016/S0021-9258(18)31492-3

55. May AE, Kanse SM, Lund LR, Gisler RH, Imhof BA, Preissner KT. Urokinase receptor (CD87) regulates leukocyte recruitment via beta 2 integrins in vivo. J Exp Med. (1998) 188:1029-37. doi: 10.1084/jem.188.6.1029
56. Montuori N, Visconte V, Rossi G, Ragno P. Soluble and cleaved forms of the urokinase-receptor: degradation products or active molecules? Thromb Haemost. (2005) 93:192-8. doi: 10.1160/TH04-09-0580

57. Mustjoki S, Sidenius N, Sier CF, Blasi F, Elonen E, Alitalo R, et al. Soluble urokinase receptor levels correlate with number of circulating tumor cells in acute myeloid leukemia and decrease rapidly during chemotherapy. Cancer Res. (2000) 60:7126-32.

58. Sidenius N, Sier CF, Blasi F. Shedding and cleavage of the urokinase receptor (UPAR): identification and characterisation of uPAR fragments in vitro and in vivo. FEBS Lett. (2000) 475:52-6. doi: 10.1016/S0014-5793(00)01624-0

59. Hoyer-Hansen G, Behrendt N, Ploug M, Dano K, Preissner KT. The intact urokinase receptor is required for efficient vitronectin binding: receptor cleavage prevents ligand interaction. FEBS Lett. (1997) 420:7985. doi: 10.1016/S0014-5793(97)01491-9

60. Fazioli F, Resnati M, Sidenius N, Higashimoto Y, Appella E, Blasi F. A urokinase-sensitive region of the human urokinase receptor is responsible for its chemotactic activity. $E M B O \quad J . \quad(1997) \quad 16: 7279-86$. doi: 10.1093/emboj/16.24. 7279

61. Behrendt N, Ronne E, Dano K. Domain interplay in the urokinase receptor. Requirement for the third domain in high affinity ligand binding and demonstration of ligand contact sites in distinct receptor domains. J Biol Chem. (1996) 271:22885-94. doi: 10.1074/jbc.271.37.2 2885

62. Behrendt N, Ronne E, Ploug M, Petri T, Lober D, Nielsen LS, et al. The human receptor for urokinase plasminogen activator. NH2-terminal amino acid sequence and glycosylation variants. J Biol Chem. (1990) 265:6453-60. doi: 10.1016/S0021-9258(19)39 $348-2$

63. Ploug $M$, Rahbek-Nielsen $H$, Nielsen PF, Roepstorff $P$, Dano K. Glycosylation profile of a recombinant urokinase-type plasminogen activator receptor expressed in Chinese hamster ovary cells. J Biol Chem. (1998) 273:13933-43. doi: 10.1074/jbc.273.22.1 3933

64. Dowsett J, Ferkingstad E, Rasmussen LJH, Thorner LW, Magnusson MK, Sugden K, et al. Eleven genomic loci affect plasma levels of chronic inflammation marker soluble urokinase-type plasminogen activator receptor. Commun Biol. (2021) 4:655. doi: 10.1038/s42003-021-02144-8

65. Stewart CE, Hall IP, Parker SG, Moffat MF, Wardlaw AJ, Connolly MJ, et al. PLAUR polymorphisms and lung function in UK smokers. BMC Med Genet. (2009) 10:112. doi: 10.1186/1471-2350-10-112

66. Kristensen P, Eriksen J, Blasi F, Dano K. Two alternatively spliced mouse urokinase receptor mRNAs with different histological localization in the gastrointestinal tract. J Cell Biol. (1991) 115:1763-71. doi: 10.1083/jcb.115.6.1763

67. Pyke C, Eriksen J, Solberg H, Nielsen BS, Kristensen P, Lund LR, et al. An alternatively spliced variant of mRNA for the human receptor for urokinase plasminogen activator. FEBS Lett. (1993) 326:69-74. doi: 10.1016/0014-5793(93)81763-P

68. Suh TT, Nerlov C, Dano K, Degen JL. The murine urokinase-type plasminogen activator receptor gene. $J$ Biol Chem. (1994) 269:25992-8. doi: 10.1016/S0021-9258(18)47 149-9

69. Hagemann-Jensen $M$, Ziegenhain C, Chen P, Ramskold D, Hendriks GJ, Larsson AJM, et al. Single-cell RNA counting at allele and isoform resolution using Smart-seq3. Nat Biotechnol. (2020) 38:708-14. doi: 10.1038/s41587-020-0 497-0

70. Winnicki W, Sunder-Plassmann G, Sengolge G, Handisurya A, Herkner $\mathrm{H}$, Kornauth $\mathrm{C}$, et al. Diagnostic and prognostic value of soluble urokinase-type plasminogen activator receptor (suPAR) in focal segmental glomerulosclerosis and impact of detection method. Sci Rep. (2019) 9:13783. doi: 10.1038/s41598-019-50 405-8

Conflict of Interest: JR reports personal fees from Biomarin, Visterra, Astellas, Genentech, Merck, Gerson Lehrman Group, and Massachusetts General Hospital. He is the recipient of grants from Nephcure Kidney International 
and Thermo BCT. JR's lab is the recipient of fee-for-service funds from Walden Biosciences. JR is cofounder, scientific advisory board cochair, and shareholder of Walden Biosciences, a kidney therapeutic company. In addition, JR has the following patents: US20110212083, Role of soluble UPAR in the pathogenesis of proteinuric kidney disease; US9867923, Reducing soluble urokinase receptor in the circulation; JP2016530510, Non-glycoslyated suPAR biomarkers and uses thereof; US20160296592, Methods/compositions for the treatment of proteinuric diseases; US9144594, Dynamin mediated diseases; and US8809386, Dynamin ring stabilizers. EH is an inventor on a patent application of inducible costimulator ligand for use as a renal therapeutic.

The remaining authors declare that the research was conducted in the absence of any commercial or financial relationships that could be construed as a potential conflict of interest.
Publisher's Note: All claims expressed in this article are solely those of the authors and do not necessarily represent those of their affiliated organizations, or those of the publisher, the editors and the reviewers. Any product that may be evaluated in this article, or claim that may be made by its manufacturer, is not guaranteed or endorsed by the publisher.

Copyright $\odot 2021$ Wei, Spear, Hahm and Reiser. This is an open-access article distributed under the terms of the Creative Commons Attribution License (CC BY).

The use, distribution or reproduction in other forums is permitted, provided the original author(s) and the copyright owner(s) are credited and that the original publication in this journal is cited, in accordance with accepted academic practice. No use, distribution or reproduction is permitted which does not comply with these terms. 